\title{
Epidemiology of myopia and prevention of myopia progression in children in East Asia: a review
}

\author{
CY Mak, Jason CS Yam, LJ Chen, SM Lee, Alvin L Young *
}

\section{A B S T R A C T}

Introduction: Myopia (short-sightedness) exhibits high prevalence in East Asia. Methods to mitigate myopia progression are important in preventing the vision-threatening complications associated with high myopia. In this review, we examine the regional epidemiology of myopia and provide updated evidence regarding interventions to slow myopia progression in children.

Methods: We performed a literature search using PubMed from the date of inception through 25 June 2018. Studies involving myopia epidemiology and control of myopia progression were selected; only studies published in English were reviewed. Preference was given to prospective studies, as well as those conducted in Hong Kong or East Asia.

Results: Atropine eye drops and pirenzepine eye gel are highly effective for controlling myopia progression in children. Orthokeratology, peripheral defocus contact lenses, bifocal or progressive addition spectacles, and increased involvement in outdoor activities are also effective for controlling myopia progression; however, myopia undercorrection and
Conclusion: Although various methods are effective for controlling myopia progression in children, no curative remedy exists for myopia. Health care professionals should be aware of the available methods, as well as their risks and benefits. Treatment should be individualised and based on the preferences of the patient's family, after full discussion of the risks and benefits of each modality.

\author{
Hong Kong Med J 2018;24:602-9 \\ DOI: $10.12809 / \mathrm{hkmj} 187513$ \\ 1,2 CY Mak, MB, BS, MRCSEd (Ophth) \\ 2 JCS Yam, FRCS (Edin), FCOphth HK \\ 1,2 LJ Chen, MRCSEd (Ophth), PhD \\ ${ }^{3}$ SM Lee, MB BCh BAO, DFM \\ 1,2 AL Young *, FRCOphth, FHKAM (Ophthalmology) \\ Department of Ophthalmology and Visual Sciences, Prince of Wales \\ Hospital, Shatin, Hong Kong \\ ${ }^{2}$ Department of Ophthalmology and Visual Sciences, The Chinese \\ University of Hong Kong, Shatin, Hong Kong \\ Private Practice \\ * Corresponding author: youngla@ha.org.hk
}

\section{Introduction}

Myopia is a prevalent eye disorder in children and adolescents in Hong Kong, which requires the use of spectacles or contact lenses for optimal vision. The complications of high myopia can be visionthreatening; therefore, clinicians and parents have great interest in controlling myopia progression in children, which may prevent the complications of myopia that can occur in adulthood. In this review, we examine recent publications regarding myopia epidemiology and interventions for controlling myopia progression in children.

\section{Methods}

We performed a literature search using PubMed from the date of inception through 25 June 2018. Studies involving myopia epidemiology and control of myopia progression were selected; only studies published in English were reviewed. In the selection of representative articles for each therapeutic intervention to control myopia progression, prospective studies were ranked higher than retrospective studies. Among prospective studies, preference was given to randomised and controlled trials, as well as studies conducted in Hong Kong or East Asia.

\section{Definition}

Myopia is a refractive disorder in which distant light entering a non-accommodating eye is focused in front of, rather than on, the retina. Myopia is categorised as axial or refractive myopia. Axial myopia is more common and results from an elongated eyeball; the onset and progression of axial myopia occur during childhood and adolescence. Conversely, refractive myopia is relatively uncommon, and involves the refractive elements of the eye; examples include index myopia, observed in patients with the nuclear sclerosis form of cataract, and curvature myopia, observed in patients with abnormal corneal curvature. Because most available studies were performed on axial myopia, this review solely focuses on axial myopia.

Myopia is optically measured in terms of dioptres (D). In Hong Kong, one dioptre of myopic 
refractive error $(-1.0 \mathrm{D})$ is colloquially referred as 100 "degrees" by opticians and the general public. Another measure closely related to the refractive state of the eye is the axial length, which is the length of the eyeball from anterior to posterior poles. An adult emmetropic eye (without refractive error) typically exhibits an axial length of 22 to $25 \mathrm{~mm}^{1}$; as a reference value for East Asian populations, the mean axial length in a large cohort of Chinese adults was $23.3 \mathrm{~mm}^{2}$

High myopia is commonly defined as myopic refraction greater than -6.0 D (600 "degrees") or axial length $>26 \mathrm{~mm},{ }^{3}$ whereas pathologic myopia is defined as high myopia with the presence of myopic maculopathy, as determined by an international photographic classification system. ${ }^{4}$

\section{Regional epidemiology}

The current epidemic of myopia is well-known in the developed countries of East Asia. A high prevalence of myopia has been reported by many countries with populations of Chinese ancestry. ${ }^{5}$ There is an increasing incidence of myopia in Hong Kong children: a local study showed that the rate of myopia in preschool children increased from $2.3 \%$ to $6.3 \%$ over 10 years. ${ }^{6}$ Additionally, there is a high prevalence of myopia in Hong Kong children: $18.3 \%$ at 6 years of age and $61.5 \%$ at 12 years of age ${ }^{7}$; the prevalence of high myopia (greater than $-6.0 \mathrm{D}$ ) in the same cohort of Hong Kong children was $0.7 \%$ at 6 years of age and $3.8 \%$ at 12 years of age. ${ }^{7}$

There are minimal data regarding the prevalence of myopia in Hong Kong adults, with the exception of a small study performed 20 years prior to this review, which showed a prevalence of $41.1 \%$ in Hong Kong adults aged $\geq 40$ years. ${ }^{8}$ Notably, the ongoing population-based epidemiological cohort of the Hong Kong Children Eye Study will provide updated information regarding myopia prevalence in schoolchildren 6 to 8 years of age, as well as their parents. For comparison, the Beijing Eye Study showed a myopia prevalence of $21.8 \%$ in adults aged $\geq 40$ years ${ }^{9}$; in Taiwan, a study of male military conscripts, aged 18 to 24 years, demonstrated an extremely high prevalence of myopia $(86.1 \%)$ with a mean refractive error of $-3.66 \mathrm{D} .^{10}$

\section{Regional population genetics}

Myopia comprises a multifactorial disease, which is affected by the interaction of environmental and genetic risk factors. Differences in myopia prevalence between East Asia and Western nations may arise as a result of lifestyle discrepancies, as well as differences in ethnicity and in population genetics. Thus far, a large number of myopia-linked genetic loci have been identified by genome-wide association studies and candidate gene-based association studies;

\section{東亞地區的近視流行性及控制兒童近視加深方法} 概覽

麥隹愉、任卓昇、陳理佳、李詩眉、楊樂旼

引言：近視在東亞地區十分普遍, 控制近視加深能預防深近視引起的 併發症。本文旨在概覽東亞地區的近視流行性, 同時提供經科學實證 的控制兒童近視加深方法

方法：通過PubMed數據庫搜索至2018年6月25日為止有關近視流行 性及控制近視加深方法的文獻。本研究只選取英語文章, 並着重於前 瞻性研究和在香港及東亞進行的研究。

結果：阿托品眼藥水和哌侖西平眼凝膠對控制兒童近視加深非常有 效。角膜塑型術、周邊散焦隱形眼鏡、雙焦距或漸進眼鏡以及增加戶 外活動亦有效控制近視加深。近視矯正不足和單焦距隱形眼鏡則不能 有效控制近視加深。

結論：儘管有不同控制兒童近視加深的方法, 惟近視至今仍未能根治 或逆轉。醫護人員應知悉各種治療方法及其好壞, 並在制訂控制近視 加深的治療方針時考慮兒童個人因素及家人意願。

detailed information regarding the prevalences of these loci in different populations has recently been reviewed. ${ }^{11}$ Genetic loci associated with myopia in the Hong Kong Chinese include $P A X 6,{ }^{11,12}$ $Z F H X 1 B,{ }^{13}$ VIPR2, ${ }^{14}$ SNTB1, ${ }^{14}$ TGIF, ${ }^{15} 13 \mathrm{q} 12.12,{ }^{16}$ and $5 \mathrm{p} 15 .{ }^{17}$ The roles of these genes and loci in myopia pathogenesis and clinical manifestation are not yet known. Further investigations of the relationships between genotype and phenotype, as well as functional characterisations of these genes and loci, are warranted.

\section{Complications of myopia}

Myopia is associated with a wide range of complications, many of which are vision-threatening and may cause blindness. A large, population-based study in Beijing revealed that degenerative myopia was the most common cause of visual impairment and blindness in adults aged 40 to 49 years; it was the second most common cause (after cataract) in adults aged $\geq 50$ years. ${ }^{18}$ The specific pathogenic mechanisms of myopia-related complications have not yet been elucidated. Mechanical stretching may play a major role, because progressive elongation of the globe in high myopia places strain on the sclera, peripapillary region, choroid, and retina. ${ }^{19}$ Thinning of these structures can cause many of the degenerative complications observed in high myopia; these complications are summarised in Table 1.

\section{Pharmacological agents to control myopia progression}

\section{Atropine eye drops}

Atropine eye drops have been widely used by 
TABLE I. Complications associated with high myopia

\begin{tabular}{ll}
\hline Optic nerve and optic disc abnormalities & $\begin{array}{l}\text { Glaucoma } \\
\text { Peripapillary atrophy }\end{array}$ \\
\hline Medical retinal complications & $\begin{array}{l}\text { Chorioretinal atrophy } \\
\text { Choroidal neovascularisation }\end{array}$ \\
Surgical retinal complications & $\begin{array}{l}\text { Peripheral retinal degeneration } \\
\text { Rhegmatogenous retinal detachment } \\
\text { Myopic macular hole } \\
\text { Myopic traction maculopathy }\end{array}$ \\
\hline
\end{tabular}

ophthalmologists for pupil dilation and cycloplegic refraction. Atropine is a non-specific muscarinic acetylcholine receptor antagonist, available as a $1 \%$ topical solution; the earliest reports of its clinical effect on myopia progression were published in the 1970s-monocular application of atropine in children caused a significant reduction of myopia progression, compared with the fellow eye..$^{20,21}$ The mechanism of atropine is not entirely known. Through experimental animal models, two theories have been hypothesised to explain the effect of atropine..$^{22}$ The first theory is that atropine interacts with M1/M4 receptors in the retina and inhibits eyeball elongation via a neurochemical cascade; the second theory is that atropine directly inhibits glycosaminoglycan synthesis by scleral fibroblasts.

The Atropine for the Treatment of Myopia study (ATOM1) was a double-masked, randomised placebo-controlled trial of atropine eye drops, which involved 400 Singaporean children with myopia. ${ }^{23}$ Application of $1 \%$ atropine eye drops in one eye each night significantly reduced myopia progression and axial elongation over the 2-year study period, compared with control $(-0.28 \mathrm{D}$ vs $-1.2 \mathrm{D}$ and $-0.02 \mathrm{~mm}$ vs $+0.38 \mathrm{~mm}$, respectively). No theoretical anticholinergic systemic adverse effects of dry mouth, skin flushing, constipation, or urinary difficulty were reported. However, adverse effects were reported, such that some children were withdrawn from the study; these included allergic reaction, glare due to pupil dilation, and blurred near vision due to cycloplegia. Of note, children in the ATOM1 study wore photochromatic spectacles, because the pupil dilation effect of $1 \%$ atropine can cause photophobia. A follow-up study of ATOM1 participants revealed that the effect of atropine on cycloplegia was fully reversible after cessation of eye drops. ${ }^{24}$

A subsequent trial, the ATOM2 study, evaluated lower concentrations of atropine: $0.5 \%, 0.1 \%$, and $0.01 \% .^{25}$ Dose-related control of myopia was shown with administration of atropine, but the differences were clinically small. Two-year measurements of myopia progression were $-0.30 \mathrm{D},-0.38 \mathrm{D}$ and -0.49 $\mathrm{D}$ in the $0.5 \%, 0.1 \%$ and $0.01 \%$ atropine groups, respectively $(\mathrm{P}=0.02$ between $0.5 \%$ and $0.01 \%$ groups;
$\mathrm{P}>0.05$ between other concentrations). However, $0.01 \%$ atropine showed a negligible effect with respect to accommodation and pupil size; its effect on near visual acuity was nearly absent. Therefore, the investigators concluded that $0.01 \%$ atropine had minimal adverse effects, compared with $0.1 \%$ and $0.5 \%$ atropine, and that it retained a comparable effect on myopia progression. Importantly, the ATOM2 study was limited by the lack of a placebo group; thus, the role of low-concentration atropine in myopia control is uncertain.

Recently, the Low-concentration Atropine for Myopia Progression study was conducted in Hong Kong. ${ }^{26}$ This was the first-ever placebo-controlled trial of low-concentration atropine eye drops to confirm their efficacy in myopia control. A total of 438 Chinese children, 4 to 12 years of age, were randomly assigned in a 1:1:1:1 ratio to receive $0.05 \%$, $0.025 \%$ or $0.01 \%$ atropine, or placebo eye drops, respectively, once nightly to both eyes, for 1 year. After 1 year, the mean measurements of myopia progression were $-0.27 \mathrm{D},-0.46 \mathrm{D},-0.59 \mathrm{D}$ and -0.81 $\mathrm{D}$ in the atropine $0.05 \%, 0.025 \%, 0.01 \%$ and placebo groups, respectively $(\mathrm{P}<0.001)$; the respective mean increases in axial length were $0.20 \mathrm{~mm}, 0.29$ $\mathrm{mm}, 0.36 \mathrm{~mm}$, and $0.41 \mathrm{~mm}(\mathrm{P}<0.001)$. There were no effects on distant or near visual acuity, or on vision-related quality of life, in any of the groups. The authors concluded that $0.05 \%, 0.025 \%$, and $0.01 \%$ atropine eye drops could reduce myopia progression in a dose-dependent manner. Of the three concentrations used, $0.05 \%$ atropine was most effective for controlling myopia progression and axial elongation during the study period.

Following demonstration of the efficacy of various concentrations of atropine by ATOM1 and ATOM2, it was important to determine whether the treatment effect remained after cessation of therapy. A follow-up study of ATOM1 participants demonstrated that 1 year after cessation of $1 \%$ atropine drops, myopia progression in the atropinetreated group was $-1.14 \mathrm{D}$, compared with -0.38 $\mathrm{D}$ in the placebo-treated group ${ }^{24}$; thus, there was a clear rebound phenomenon. A similar rebound phenomenon with respect to myopia progression was also observed among ATOM2 subjects; notably, this effect was dose-related-greater rebound was observed in groups that had used higher concentrations of atropine. ${ }^{27}$

To investigate prevention of the onset of myopia, a retrospective study in Taiwan compared pre-myopic children who received $0.025 \%$ atropine over a 1-year period with those who did not. Myopic shift was significantly lower in the atropine-treated group (-0.14 D vs $-0.58 \mathrm{D}){ }^{28}$

The ATOM1 and ATOM2 studies led to increased interest in the use of atropine among Hong Kong ophthalmologists. However, the sole 
concentration of atropine eye drops commercially available in Hong Kong public hospitals is $1 \%$; the usage of this dose has been associated with significant adverse effects, as noted above. At this stage, the use of atropine eye drops as a measure to mitigate myopia progression is not yet readily available in the public sector, as none of the drugs are registered with the Department of Health. Lower-concentration eye drops either must be ordered on an individual patient basis, or prepared in collaboration with pharmacies and used in an off-label manner.

\section{Pirenzepine eye gel}

Pirenzepine is a selective muscarinic M1 acetylcholine receptor antagonist. A randomised placebocontrolled multicentre study, including 353 myopic children from Hong Kong, Singapore, and Thailand, showed myopia progression of $-0.47 \mathrm{D},-0.70 \mathrm{D}$ and $-0.84 \mathrm{D}$ in the $2 \%$ gel twice daily, $2 \%$ gel once daily and placebo twice daily groups, respectively. ${ }^{29}$ The difference between the pirenzepine $2 \%$ gel twice daily and placebo twice daily groups reached statistical significance $(\mathrm{P}<0.001)$. However, pirenzepine is not commercially available.

\section{Optical means to control myopia progression}

\section{Myopia undercorrection}

Early animal models ${ }^{30}$ showed that convex lensinduced myopic defocus could inhibit axial elongation of the globe; thus, researchers attempted to control myopia progression in humans via undercorrection with spectacles. Prospective randomised clinical trials showed that undercorrection of myopia, such as by under-prescription of spectacles by $0.5 \mathrm{D}$ to 0.75 $D$, either did not significantly affect myopia control ${ }^{31}$ or worsened myopia progression ${ }^{32}$ compared with full spectacle prescription; this lack of effect was supported by data from a recent non-interventional large-scale prospective Chinese cohort. ${ }^{33}$

\section{Contact lenses}

In the 1990s, contact lens usage received substantial interest as a method to control myopia progression. At the time, it was speculated that by flattening the cornea, the contact lens might slow axial elongation. However, randomised controlled trials (RCTs) showed that both soft contact lenses ${ }^{34}$ and rigid gas permeable (RGP) lenses ${ }^{35}$ were ineffective in slowing myopia progression, compared with spectacles as control.

A randomised study comparing RGP lenses and soft contact lenses found significant reduction in myopia progression over 3 years in the RGP lens group $(-1.56 \mathrm{D}$ vs $-2.19 \mathrm{D}) .{ }^{36}$ However, axial elongation did not significantly differ between the two groups, suggesting that the apparent slowing of myopia progression might be a result of corneal flattening by RGP lenses, which is reversible upon discontinuation of RGP lens usage.

\section{Bifocal or progressive addition spectacles}

Bifocal or progressive addition spectacles contain multifocal lenses of two or more distinct optical powers. They are more commonly used in people aged $\geq 40$ years with presbyopia, because differing optical powers allow clear vision at various distances. The use of these spectacles has also been evaluated for control of myopia in children. Notably, bifocal or progressive addition spectacles are speculated to reduce accommodative effort during near work, which may reduce peripheral retinal hyperopic defocus and slow myopia progression.

A meta-analysis from the Cochrane Library ${ }^{37}$ evaluated eight studies, including one from Hong Kong, ${ }^{38}$ which investigated the effect of bifocal or progressive addition spectacles in slowing myopia progression. Pooled data suggested that average myopia progression at 1 year was $0.16 \mathrm{D}$ slower for wearers of multifocal spectacles than for wearers of single vision spectacles. Although the effect was statistically significant, it was regarded as insufficient for clinical use. A targeted trial was then designed to evaluate the effect of progressive addition lenses in children with a high lag of accommodation, a condition suspected to respond best to multifocal lenses $^{39}$; the results showed a similar statistically significant, but clinically modest, $0.18 \mathrm{D}$ reduction in myopia progression at 1 year in the progressive addition lens group, compared with the single vision lens group.

Despite its clinically modest effect, the use of multifocal lenses is a popular myopia control modality advocated by some Hong Kong optometrists, because it is readily available and safe.

\section{Orthokeratology}

Orthokeratology, known in Hong Kong as orthokeratology lens, consists of reverse geometry contact lenses which are worn by children overnight and removed upon waking. This method provides the convenience of spectacle-free vision during daytime, as it flattens the cornea during nighttime wear. An RCT conducted in Hong Kong, the Retardation of Myopia in Orthokeratology study, ${ }^{40}$ showed a significant effect of orthokeratology in controlling axial elongation at 2 years, compared with control (single vision glasses), in children with low-tomoderate myopia (+0.36 $\mathrm{mm}$ vs $+0.63 \mathrm{~mm})$. Another $\mathrm{RCT}$ in Hong Kong showed a significant effect of orthokeratology in children with high myopia, compared with control, in limiting axial elongation at 2 years $(+0.19 \mathrm{~mm}$ vs $+0.51 \mathrm{~mm}){ }^{41}$ 
Although orthokeratology has shown promising results in controlling axial elongation, the long-term effects of this method remain unknown. In particular, whether discontinuation may result in rebound of myopia is unclear. The application of contact lenses in children may be difficult; this difficulty is greater among younger children. In addition, during the nocturnal usage of any contact lens, there is an inherent increased risk of corneal infection. Moreover, the natural rebound to its original corneal contour during the daytime complicates the use of orthokeratology in high myopes, as there is a myopic shift towards the end of the day, which leads to deteriorating vision over time. The vision-threatening complication of infectious keratitis remains an important concern, as there have been reports of corneal ulcers in Hong Kong children using orthokeratology lenses. ${ }^{42}$ More than 160 cases of orthokeratology-associated infectious keratitis have been reported in the literature; Pseudomonas aeruginosa and Acanthamoeba are the most common aetiological agents. ${ }^{43}$ In addition, children with atopy are likely to be intolerant of contact lenses.

Orthokeratology is unavailable in public hospitals in Hong Kong, but is a common practice by many optometrists and some private ophthalmologists in Hong Kong. The potential benefits of orthokeratology in slowing myopia progression must be weighed against the risks of vision-threatening infectious keratitis.

\section{Peripheral retinal defocus}

Research in animal models has shown that the refractive state of the peripheral retina can affect eye growth. ${ }^{44,45}$ Peripheral retinal myopic defocus, achieved by imposing a convex refractive element, can inhibit axial elongation in growing animals.

An RCT was performed involving 221 myopic children in Hong Kong to evaluate the effect of defocus incorporated soft contact (DISC) lenses, compared with single vision contact lenses as control. ${ }^{46}$ The DISC lenses achieve peripheral retinal defocus by incorporating concentric rings that provide an addition of $+2.5 \mathrm{D}$, in a manner that alternates with normal distance correction. Over a 1-year period, significant reductions in myopia progression and axial elongation were noted in the DISC group $(-0.30 \mathrm{D}$ vs $-0.40 \mathrm{D}$ and $+0.13 \mathrm{~mm}$ vs $+0.18 \mathrm{~mm}$, respectively). Importantly, achievement of myopia progression slowing of $46 \%$ required wearing the DISC lenses for a minimum of 5 hours per day. However, there was a high dropout rate of $42 \%$ in the study, likely because of the practical difficulties associated with contact lens use in children. The potential risk of infectious keratitis was also a major concern for clinicians involved in the study.
Because of the inconvenience and risk of contact lens use in children, defocus incorporated multiple segments (DIMS) spectacle lenses have been developed by a local university in Hong Kong. The lenses comprise a central optical zone used to correct myopia, combined with multiple segments of myopic defocus around the central zone, which extend to the mid-periphery of the lens. Preliminary results suggest a significant effect of DIMS in slowing myopia progression and axial elongation, compared with control. ${ }^{47}$ Thus far, DIMS spectacles are not yet commercially available in Hong Kong.

\section{Lifestyle modification for control of myopia progression}

\section{Outdoor activity}

Epidemiological studies have demonstrated a difference in the prevalence of myopia in urban and rural areas; thus, outdoor activity has been hypothesised to affect myopia onset and progression, because much less time is spent outdoors in many urban areas. A meta-analysis of seven cross-sectional studies reported a $2 \%$ reduction in the odds of myopia per additional hour of time spent outdoors per week. ${ }^{48}$

Prospective studies have been conducted to examine the effect of outdoor activity as an intervention. A recent randomised study in Taiwan included 16 schools: intervention schools implemented a programme to remove children from the classroom during recess and encourage them to participate in outdoor activities. ${ }^{49}$ Myopia progression and axial elongation were significantly reduced in the intervention group, compared with control $(-0.35 \mathrm{D}$ vs $-0.47 \mathrm{D}$ and $+0.28 \mathrm{~mm}$ vs $+0.33 \mathrm{~mm}$, respectively). A similar study in Taiwan, which compared two neighbouring schools, found a significantly lower rate of myopia onset in the intervention group $(8.41 \%$ vs $17.65 \%){ }^{50} \mathrm{~A}$ similar significant effect on incident myopia was revealed in a prospective study in Guangzhou, China: intervention schools had a 40-minute outdoor activity class added to each school day. ${ }^{51}$ Three-year cumulative incident myopia was significantly lower in the intervention group (30.4\% vs $39.5 \%)$; however, there were no significant differences in axial elongation between the intervention and control groups $(+0.95 \mathrm{~mm}$ vs $+0.98 \mathrm{~mm} ; \mathrm{P}=0.07$ ). Thus, outdoor activity may slow myopia onset, but its effect on myopia progression is not yet clear.

The aetiology of this protective effect against myopia onset is uncertain. Animal models suggest that light exposure can stimulate retinal dopaminergic pathways, which then interfere with eye growth signalling pathways, preventing excessive elongation of the eyeball. ${ }^{52}$ Given the academic pressures and generally urban lifestyle among Hong 
TABLE 2. Interventions for controlling myopia progression in children

\begin{tabular}{|c|c|c|}
\hline Efficacy * & Interventions & Remarks \\
\hline \multirow[t]{2}{*}{$\begin{array}{l}\text { High } \\
>0.50 \text { D/year* }\end{array}$} & $\begin{array}{l}\text { Atropine } 1 \%^{23} \\
\text { Atropine } 0.5 \% \text { and } 0.1 \% 25 \\
\text { Atropine } 0.05 \%, 0.025 \% \text { and } 0.01 \%{ }^{26}\end{array}$ & $\begin{array}{l}\text { Atropine } 1 \% \text { is the sole concentration commercially available in } \\
\text { Hong Kong }\end{array}$ \\
\hline & Pirenzepine $2 \%{ }^{29}$ & Not commercially available in Hong Kong \\
\hline \multirow{2}{*}{$\begin{array}{l}\text { Moderate } \\
0.25-0.50 \text { D/year* }\end{array}$} & Orthokeratology ${ }^{40,41}$ & Risk of infectious keratitis with nocturnal wear \\
\hline & Peripheral defocus contact lens ${ }^{46}$ & Risk of infectious keratitis \\
\hline \multirow{2}{*}{$\begin{array}{l}\text { Low } \\
0-0.25 \text { D/year* }\end{array}$} & Bifocal or progressive addition spectacles ${ }^{38,39}$ & \\
\hline & Increased outdoor activities ${ }^{49-51}$ & \\
\hline \multirow[t]{2}{*}{ Unproven } & Myopia undercorrection ${ }^{31}$ & May accelerate myopia progression ${ }^{32}$ \\
\hline & Single vision contact lens (soft ${ }^{34}$ or RGP ${ }^{35}$ ) & \\
\hline \multirow[t]{2}{*}{ Require further evidence } & Reduction of near work & No RCT available \\
\hline & Peripheral defocus spectacle lens & $\begin{array}{l}\text { RCT data not yet published in a peer-reviewed journal } \\
\text { Not yet commercially available in Hong Kong }\end{array}$ \\
\hline
\end{tabular}

Abbreviations: $\mathrm{D}=$ dioptres; $\mathrm{RCT}=$ randomised controlled trials; $\mathrm{RGP}=$ rigid gas permeable

* Efficacy compared with single vision spectacles as control, calculated via a network meta-analysis of $30 \mathrm{RCTs}^{56}$

Kong children, this intervention may be effective, but is likely to be difficult to implement in the greater context of public health.

\section{Near work}

Near work is regarded by the general public as a risk factor for myopia development and myopia progression. However, evidence is conflicting, and the quantification of near work is often difficult. A meta-analysis of 27 studies (including 14 from Asia) found higher odds of myopia (odds ratio=1.14) associated with longer periods of time devoted to near work. ${ }^{53}$ However, reports from Beijing ${ }^{54}$ and Singapore $^{55}$ showed no significant effect of near work on myopia.

Thus far, there have been no prospective controlled trials regarding near work reduction as an intervention to control myopia progression.

\section{Summary of interventions to control myopia progression}

Cross-comparisons between interventions for controlling myopia progression are difficult, owing to intrinsic differences in study design and baseline patient characteristics. A recent network metaanalysis included $30 \mathrm{RCTs}$ in attempt to crosscompare the efficacies of interventions for slowing myopia progression in children. ${ }^{56}$ The most effective interventions were atropine and pirenzepine, followed by orthokeratology and peripheral defocus contact lenses. Multifocal spectacles and increased periods of outdoor activity were also found to be useful, but these effects were modest. Notably, combinations of these modalities have not been assessed to determine whether they might have additional effects. Interventions for controlling myopia progression discussed in this review are summarised in Table 2. . $3,25,26,29,31,32,34,35,38-41,46,49-51,56^{-}$

\section{Conclusion}

There is an epidemic of myopia in East Asia, and local data suggest a high prevalence of myopia in Hong Kong children. Genetic studies have revealed a few loci associated with myopia in Hong Kong Chinese; however, the exact mechanisms of these loci are not yet known. Clinical trials have provided strong evidence regarding the efficacy of several interventions to control myopia progression in children. However, there are practical concerns, because some interventions (eg, concentrations of atropine $<1 \%$, as well as pirenzepine) are not currently available in Hong Kong. Moreover, some interventions (eg, orthokeratology and peripheral defocus contact lens) have potential visionthreatening adverse effects.

\section{Author contributions}

Concept and design: CY Mak, AL Young.

Acquisition of data: CY Mak, JCS Yam, LJ Chen.

Analysis and interpretation of data: CY Mak, JCS Yam, LJ Chen.

Drafting of the article: All authors.

Critical revision for important intellectual content: All authors.

\section{Declaration}

All authors have disclosed no conflicts of interest. All authors had full access to the data, contributed to the study, approved the final version for publication, and take responsibility for its accuracy and integrity. 


\section{References}

1. Bhardwaj V, Rajeshbhai GP. Axial length, anterior chamber depth-a study in different age groups and refractive errors. J Clin Diagn Res 2013;7:2211-2.

2. Yin G, Wang YX, Zheng ZY, et al. Ocular axial length and its associations in Chinese: the Beijing Eye Study. PLoS One 2012; 7:e43172.

3. Ohno-Matsui K. Pathologic myopia. Asia Pac J Ophthalmol (Phila) 2016;5:415-23.

4. Ohno-Matsui K, Kawasaki R, Jonas JB, et al. International photographic classification and grading system for myopic maculopathy. Am J Ophthalmol 2015;159:877-83.e7.

5. Wu PC, Huang HM, Yu HJ, Fang PC, Chen CT. Epidemiology of myopia. Asia Pac J Ophthalmol (Phila) 2016;5:386-93.

6. Fan DS, Lai C, Lau HH, Cheung EY, Lam DS. Change in vision disorders among Hong Kong preschoolers in 10 years. Clin Exp Ophthalmol 2011;39:398-403.

7. Lam CS, Lam CH, Cheng SC, Chan LY. Prevalence of myopia among Hong Kong Chinese schoolchildren: changes over two decades. Ophthalmic Physiol Opt 2012;32:17-24.

8. van Newkirk MR. The Hong Kong vision study: a pilot assessment of visual impairment in adults. Trans Am Ophthalmol Soc 1997;95:715-49.

9. Xu L, Li J, Cui T, et al. Refractive error in urban and rural adult Chinese in Beijing. Ophthalmology 2005;112:167683.

10. Lee YY, Lo CT, Sheu SJ, Lin JL. What factors are associated with myopia in young adults? A survey study in Taiwan military conscripts. Invest Ophthalmol Vis Sci 2013;54:1026-33.

11. Tang SM, Rong SS, Young AL, Tam PO, Pang CP, Chen LJ. PAX6 gene associated with high myopia: a meta-analysis. Optom Vis Sci 2014;91:419-29.

12. Tang SM, Ma L, Lu SY, et al. Association of the PAX6 gene with extreme myopia rather than lower grade myopias. Br J Ophthalmol 2018;102:570-4.

13. Khor CC, Miyake M, Chen LJ, et al. Genome-wide association study identifies $Z F H X 1 B$ as a susceptibility locus for severe myopia. Hum Mol Genet 2013;22:528894.

14. Shi Y, Gong B, Chen L, et al. A genome-wide meta-analysis identifies two novel loci associated with high myopia in the Han Chinese population. Hum Mol Genet 2013;22:232533.

15. Lam DS, Lee WS, Leung YF, et al. TGFbeta-induced factor: a candidate gene for high myopia. Invest Ophthalmol Vis Sci 2003;44:1012-5.

16. Shi Y, Qu J, Zhang D, et al. Genetic variants at $13 q 12.12$ are associated with high myopia in the Han Chinese population. Am J Hum Genet 2011;88:805-13.

17. Lam CY, Tam PO, Fan DS, et al. A genome-wide scan maps a novel high myopia locus to $5 p 15$. Invest Ophthalmol Vis Sci 2008;49:3768-78.

18. Xu L, Wang Y, Li Y, et al. Causes of blindness and visual impairment in urban and rural areas in Beijing: the Beijing Eye Study. Ophthalmology 2006;113:1134.e1-11.

19. Ohno-Matsui K, Lai TY, Lai CC, Cheung CM. Updates of pathologic myopia. Prog Retin Eye Res 2016;52:156-87.

20. Bedrossian RH. The effect of atropine on myopia. Ann Ophthalmol 1971;3:891-7.

21. Bedrossian RH. The effect of atropine on myopia.
Ophthalmology 1979;86:713-9.

22. Tan D, Tay SA, Loh KL, Chia A. Topical atropine in the control of myopia. Asia Pac J Ophthalmol (Phila) 2016;5:424-8.

23. Chua WH, Balakrishnan V, Chan YH, et al. Atropine for the treatment of childhood myopia. Ophthalmology 2006;113:2285-91.

24. Tong L, Huang XL, Koh AL, Zhang X, Tan DT, Chua WH. Atropine for the treatment of childhood myopia: effect on myopia progression after cessation of atropine. Ophthalmology 2009;116:572-9.

25. Chia A, Chua WH, Cheung YB, et al. Atropine for the treatment of childhood myopia: safety and efficacy of $0.5 \%$, $0.1 \%$, and $0.01 \%$ doses (Atropine for the Treatment of Myopia 2). Ophthalmology 2012;119:347-54.

26. Yam JC, Jiang Y, Tang SM, et al. Low-concentration Atropine for Myopia Progression (LAMP) study: a randomized, double-blinded, placebo-controlled trial of $0.05 \%, 0.025 \%$ and $0.01 \%$ atropine eye drops in myopia control. Ophthalmology. Available from: https://www. aaojournal.org/article/S0161-6420(18)30285-9/abstract. In press.

27. Chia A, Chua WH, Wen L, Fong A, Goon YY, Tan D. Atropine for the treatment of childhood myopia: changes after stopping atropine $0.01 \%, 0.1 \%$ and $0.5 \%$. Am J Ophthalmol 2014;157:451-7.e1.

28. Fang PC, Chung MY, Yu HJ, Wu PC. Prevention of myopia onset with $0.025 \%$ atropine in premyopic children. J Ocul Pharmacol Ther 2010;26:341-5.

29. Tan DT, Lam DS, Chua WH, Shu-Ping DF, Crockett RS; Asian Pirenzepine Study Group. One-year multicenter, double-masked, placebo-controlled, parallel safety and efficacy study of $2 \%$ pirenzepine ophthalmic gel in children with myopia. Ophthalmology 2005;112:84-91.

30. Schaeffel F, Glasser A, Howland HC. Accommodation, refractive error and eye growth in chickens. Vision Res 1988;28:639-57.

31. Adler D, Millodot M. The possible effect of undercorrection on myopic progression in children. Clin Exp Optom 2006;89:315-21.

32. Chung K, Mohidin N, O'Leary DJ. Undercorrection of myopia enhances rather than inhibits myopia progression. Vision Res 2002;42:2555-9.

33. Sun YY, Li SM, Li SY, et al. Effect of uncorrection versus full correction on myopia progression in 12-year-old children. Graefes Arch Clin Exp Ophthalmol 2017;255:189-95.

34. Horner DG, Soni PS, Salmon TO, Swartz TS. Myopia progression in adolescent wearers of soft contact lenses and spectacles. Optom Vis Sci 1999;76:474-9.

35. Katz J, Schein OD, Levy B, et al. A randomized trial of rigid gas permeable contact lenses to reduce progression of children's myopia. Am J Ophthalmol 2003;136:82-90.

36. Walline JJ, Jones LA, Mutti DO, Zadnik K. A randomized trial of the effects of rigid contact lenses on myopia progression. Arch Ophthalmol 2004;122:1760-6.

37. Walline JJ, Lindsley K, Vedula SS, Cotter SA, Mutti DO, Twelker JD. Interventions to slow progression of myopia in children. Cochrane Database Syst Rev 2011;(12):CD004916.

38. Edwards MH, Li RW, Lam CS, Lew JK, Yu BS. The Hong Kong progressive lens myopia control study: study design and main findings. Invest Ophthalmol Vis Sci 2002;43:2852-8

39. Berntsen DA, Sinnott LT, Mutti DO, Zadnik K. A 
randomized trial using progressive addition lenses to evaluate theories of myopia progression in children with a high lag of accommodation. Invest Ophthalmol Vis Sci 2012;53:640-9.

40. Cho P, Cheung SW. Retardation of myopia in Orthokeratology (ROMIO) study: a 2-year randomized clinical trial. Invest Ophthalmol Vis Sci 2012;53:7077-85.

41. Charm J, Cho P. High myopia-partial reduction ortho-k: a 2-year randomized study. Optom Vis Sci 2013;90:530-9.

42. Young AL, Leung AT, Cheng LL, Law RW, Wong AK, Lam DS. Orthokeratology lens-related corneal ulcers in children: a case series. Ophthalmology 2004;111:590-5.

43. Kam KW, Yung W, Li GK, Chen LJ, Young AL. Infectious keratitis and orthokeratology lens use: a systematic review. Infection 2017;45:727-35.

44. Benavente-Pérez A, Nour A, Troilo D. Axial eye growth and refractive error development can be modified by exposing the peripheral retina to relative myopic or hyperopic defocus. Invest Ophthalmol Vis Sci 2014;55:6765-73.

45. Liu Y, Wildsoet C. The effective add inherent in 2-zone negative lenses inhibits eye growth in myopic young chicks. Invest Ophthalmol Vis Sci 2012;53:5085-93.

46. Lam CS, Tang WC, Tse DY, Tang YY, To CH. Defocus incorporated soft contact (DISC) lens slows myopia progression in Hong Kong Chinese schoolchildren: a 2-year randomised clinical trial. Br J Ophthalmol 2014;98:40-5.

47. The Hong Kong Polytechnic University. Spectacle lens designed by PolyU slows myopic progression by $60 \%$ and stops in $21.5 \%$ of children. Appendix I. Available from: https://www.polyu.edu.hk/web/filemanager/en/
content_155/7027/Appendix.pdf. Accessed 20 May 2018.

48. Sherwin JC, Reacher MH, Keogh RH, Khawaja AP, Mackey DA, Foster PJ. The association between time spent outdoors and myopia in children and adolescents: a systematic review and meta-analysis. Ophthalmology 2012;119:2141-51.

49. Wu PC, Chen CT, Lin KK, et al. Myopia prevention and outdoor light intensity in a school-based cluster randomized trial. Ophthalmology 2018;125:1239-50.

50. Wu PC, Tsai CL, Wu HL, Yang YH, Kuo HK. Outdoor activity during class recess reduces myopia onset and progression in school children. Ophthalmology 2013;120:1080-5.

51. He M, Xiang F, Zeng Y, et al. Effect of time spent outdoors at school on the development of myopia among children in China: a randomized clinical trial. JAMA 2015;314:1142-8.

52. Feldkaemper M, Schaeffel F. An updated view on the role of dopamine in myopia. Exp Eye Res 2013;114:106-19.

53. Huang HM, Chang DS, Wu PC. The association between near work activities and myopia in children-a systematic review and meta-analysis. PLoS One 2015;10:e0140419.

54. Lin Z, Vasudevan B, Jhanji V, et al. Near work, outdoor activity, and their association with refractive error. Optom Vis Sci 2014;91:376-82.

55. Saw SM, Shankar A, Tan SB, et al. A cohort study of incident myopia in Singaporean children. Invest Ophthalmol Vis Sci 2006;47:1839-44.

56. Huang J, Wen D, Wang Q, et al. Efficacy comparison of 16 interventions for myopia control in children: a network meta-analysis. Ophthalmology 2016;123:697-708. 